\title{
The Effect of the Shear Modulus on Planes which is Perpendicular to the Crack's Edge-planes and Parallel to the Crack's Front on the ERR in an Orthotropic Rectangular Prism with a Band Crack
}

\begin{abstract}
Arzu Turan Dincel
Yıldız Teknik Üniversitesi, Kimya-Metalürji Fakültesi, Matematik Mühendisliği Bölümü, No: 127, Esenler, 34210 Istanbul e-posta : artur@yildiz.edu.tr
\end{abstract}

Geliş Tarihi: 02.08.2016 ; Kabul Tarihi: 08.03.2017

Keywords

Energy Release Rate;

Band Crack; Shear

Modulus; 3D Finite

Element Method;

Orthotropic Material.
In this study, a rectangular prism made of an orthotropic material is considered. It is assumed that this prism contains a band crack whose edge-planes are parallel to the upper and lower face planes. It is also assumed that uniformly distributed normal forces are imposed the top and bottom surface of the prism. The aim of this paper is to analyze the effect of the shear modulus on planes which is perpendicular to the crack's edge-planes and parallel to the crack's front on the Energy Release Rate (ERR) for different geometric parameters in a rectangular prism. The mathematical formulation of the corresponding boundary-value problem is carried out within the framework of the 3-dimensional linear theory of elasticity. In order to solve this problem, the 3D finite element method was employed. The numerical results are presented.

\section{Bant Çatlak Içeren Ortotropik Malzemeden Yapılmış bir Dikdörtgen Prizmada, Çatlak Düzlemine Dik ve Çatlak Yüzüne Paralel Kayma Modülünün ERR'ye Etkisi}

\begin{abstract}
Anahtar kelimeler
Enerji Salınım Oranı;

Bant çatlak, Kayma

modülü; 3 Boyutlu

Sonlu Elemanlar

Yöntemi; Ortotropik

Malzeme.

Özet

Bu çalışmada, ortotropik malzemeden yapılmış dikdörtgen prizma ele alınmıştır. Bu prizmanın bir bant çatlak içerdigi ve çatlağın düzlemlerinin, prizmanin alt ve üst düzlemlerine paralel olduğu kabul edilmiştir. Ayrıca prizmanın alt ve üst yüzeylerine düzgün yayılımlı normal kuvvetlerin etki ettiği kabul edilmiştir. Bu çalışmanın amacl; bir dikdörtgen prizmada, çatlak düzlemine dik ve çatlak yüzüne paralel olan kayma modülünün ERR'ye etkisini, farklı geometrik parametreler için incelemektir. Uygun sınır değer problemin matematiksel formülasyonu 3 boyutlu lineer elastistise teorisi çerçevesinde yapılmıştır. Bu problemi çözmek için 3 Boyutlu Sonlu Elemanlar Yöntemi kullanılmıştır. Sayısal sonuçlar sunulmuştur.
\end{abstract}

(C) Afyon Kocatepe Üniversitesi

\section{Introduction}

In recent years, the importance of fracture mechanics in engineering applications has increased considerably owing to the growing requirement to predict the behavior of cracked structures under external factors. Therefore, many structural engineers and scientists have concentrated on crack-fracture problems in order to determine the role of the parameters related to the crack's geometry and material properties, the crack's position, method of loading etc. It should be emphasized that Stress Intensity Factor (SIF) and Energy Release Rate (ERR) are critically typical fracture mechanics parameters for this determination. It is known that a wide range of such problems have been studied by many 
researchers. Approximate and exact solutions deal with ERR and SIF were tabulated in handbooks such as Tada et.al (1985) and Sih (1973).

Moreover, various methods of evaluating the SIF and ERR have been developed so far by Cherepanov (1967), Rice (1968), Shivakumar (1988), Fan et al. (2007), Knowles and Sternberg (1972), Maiti (1992), Gosz et al. (1998) etc. Based on the analyses of the above-mentioned investigations, there are many studies on the effects of the orthotropic and mechanical parameters on the SIF or on the ERR (Akbarov and Turan, 2009, Oneida et al., 2015, Ding and Li, 2014 and Yusufoğlu and Turhan, 2012). However, these studies were discussed within the framework of the two-dimensional (2D) problem formulation. A few of the investigations related to $3 D$ crack problems were carried out by Sukumar et al.(2000) and Li et al.(1998). In these studies, 3D edge crack problem for the rectangular prism was considered. This prism was made of homogeneous, isotropic material.

The present paper considers the 3D corresponding problem for a rectangular prism which contains a band crack. Moreover, it is assumed that the material of the prism is orthotropic. The aim of the present investigation is to determine the influence of the shear modulus in a plane which is perpendicular to the crack's edge-planes and parallel to the crack's front on the values of ERR for various parameters. The 3D finite elements method is utilized so as to provide a solution to the corresponding boundary-value problem.

\section{Formulation of the problem}

Consider a rectangular prism which contains a band crack at $\left\{\ell / 2-\ell_{0} / 2<x_{1}<\ell / 2+\ell_{0} / 2\right.$, $\left.\mathrm{x}_{2}=\mathrm{h}_{\ell}, 0 \leq \mathrm{x}_{3} \leq \mathrm{t}\right\}$. Assume that the prism occupies the region $\left\{0 \leq \mathrm{x}_{1} \leq \ell, 0 \leq \mathrm{x}_{2} \leq \mathrm{h}, 0 \leq \mathrm{x}_{3} \leq \mathrm{t}\right\}$ in the Cartesian Coordinate system $O \mathrm{x}_{1} \mathrm{x}_{2} \mathrm{x}_{3}$. The half-prism's geometry (i.e. the case where $0 \leq x_{1} \leq \ell / 2$ ) is shown in Figure 1.

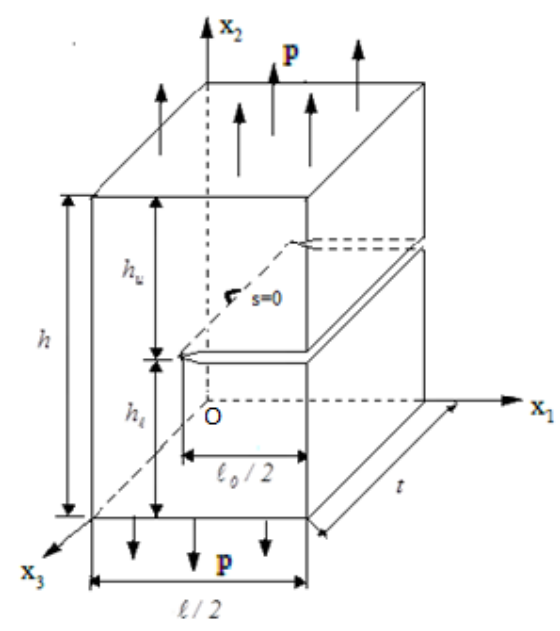

Figure 1. Considered rectangular prism geometry

Suppose that the material of the prism is orthotropic with symmetry axes $\mathrm{Ox}_{1}, \mathrm{Ox}_{2}$ and $\mathrm{Ox}_{3}$ The prism is simply supported at its ends and on upper and lower face of the prism act with intensity puniformly distributed normal forces (Figure 1). To find ERR at the band crack front is investigated stress-state in the prism. Within the framework 3D linear theory of elasticity for anisotropic bodies, the stress-state can be determined by the solution to the boundary-value problem given below:

$\frac{\partial \sigma_{1 i}}{\partial x_{1}}+\frac{\partial \sigma_{2 i}}{\partial x_{2}}+\frac{\partial \sigma_{3 i}}{\partial x_{3}}=0$

$\sigma_{i i}=A_{i 1} \varepsilon_{11}+A_{i 2} \varepsilon_{22}+A_{i 3} \varepsilon_{33}, A_{i j}=A_{j i}$,

(1)

$$
\begin{aligned}
& \sigma_{i j}=2 \mu_{i j} \varepsilon_{i j}, \text { at } i \neq j \\
& \varepsilon_{i j}=\frac{1}{2}\left(\frac{\partial u_{i}}{\partial x_{j}}+\frac{\partial u_{j}}{\partial x_{i}}\right), \quad i, j=1,2,3
\end{aligned}
$$

Boundary conditions:

$$
\begin{aligned}
& \left.\mathrm{u}_{2}\right|_{\mathrm{x}_{1}=0}=\left.\mathrm{u}_{2}\right|_{\mathrm{x}_{1}=\ell}=0,\left.\mathrm{u}_{2}\right|_{\mathrm{x}_{3}=0}=\left.\mathrm{u}_{2}\right|_{\mathrm{x}_{3}=\mathrm{t}}=0, \\
& \left.\sigma_{2 \mathrm{i}}\right|_{\mathrm{x}_{2}=0}=\left.\sigma_{2 \mathrm{i}}\right|_{\mathrm{x}_{2}=\mathrm{h}}=\mathrm{p} \delta_{\mathrm{i}}^{2},\left.\quad \sigma_{1 \mathrm{i}}\right|_{\mathrm{x}_{1}=0}=\left.\sigma_{1 \mathrm{i}}\right|_{\mathrm{x}_{1}=\ell}=0, \\
& \left.\sigma_{3 \mathrm{i}}\right|_{\mathrm{x}_{3}=0}=\left.\sigma_{3 \mathrm{i}}\right|_{\mathrm{x}_{3}=\mathrm{t}}=0
\end{aligned}
$$




$$
\begin{aligned}
& \left.\sigma_{2 \mathrm{i}}\right|_{\mathrm{x}_{2}=\mathrm{h}_{\ell \pm 0}}=0, \mathrm{i}=1,2,3 . \\
& \left(\ell / 2-\ell_{0} / 2\right)<\mathrm{x}_{1}<\left(\ell / 2+\ell_{0} / 2\right) \\
& 0<\mathrm{x}_{3}<\mathrm{t}
\end{aligned}
$$

where

$$
\begin{aligned}
& A_{i j}=(-1)^{i+j} a_{i j} \times\left(\text { det }\left\|a_{n m}\right\|\right)^{-1}, a_{11}=\frac{1}{E_{1}}, \quad a_{12}=-\frac{v_{12}}{E_{2}} \\
& a_{13}=-\frac{v_{13}}{E_{3}}, \quad a_{23}=-\frac{v_{23}}{E_{3}}, \quad a_{22}=\frac{1}{E_{2}}, \quad a_{33}=\frac{1}{E_{3}}, \\
& a_{i j}=a_{j i}, G_{i j}=\mu_{i j}, i \neq j, \quad i, j=1,2,3 .
\end{aligned}
$$

In Eq. (4), $E_{1}, E_{2}$ and $E_{3}$ denote the moduli of elasticity in the $O \mathrm{xx}_{1}, \mathrm{Ox}_{2}$ and $\mathrm{Ox}_{3}$ directions, respectively; $v_{12}, v_{23}$ and $v_{13}$ are Poisson's ratios of the material; and $\mathrm{G}_{12}, \mathrm{G}_{23}$ and $\mathrm{G}_{13}$ are the shear moduli of the material in the $O \mathrm{xx}_{1} \mathrm{x}_{2}$, $O x_{2} x_{3}$ and $O x_{1} x_{3}$ planes, respectively. (Lekhnitskii , 1981). Thus, the mathematical formulation of the problem considered is complete.

\section{FEM Modelling}

For the 3D FEM modeling of the boundary-value problem, the standard Ritz technique (Zienkiewicz and Taylor, 1989) and the following functional is used:

$$
\begin{aligned}
\Pi= & \frac{1}{2} \iiint_{\Omega-\Omega^{\prime}}\left(\sigma_{11} \varepsilon_{11}+2 \sigma_{12} \varepsilon_{12}+2 \sigma_{13} \varepsilon_{13}\right. \\
& \left.+2 \sigma_{23} \varepsilon_{23}+\sigma_{22} \varepsilon_{22}+\sigma_{33} \varepsilon_{33}\right) \mathrm{d} \Omega \\
& -\left.\int_{0}^{\mathrm{t}} \int_{0}^{\ell} \mathrm{pu}_{2}\right|_{\mathrm{x}_{2}=\mathrm{h}} \mathrm{dx} \mathrm{x}_{1} \mathrm{dx_{3 }}-\left.\int_{0}^{\mathrm{t}} \int_{0}^{\ell} \mathrm{pu}_{2}\right|_{\mathrm{x}_{2}=0} \mathrm{dx} \mathrm{dx}_{3}
\end{aligned}
$$

where

$$
\begin{gathered}
\Omega=\left\{0 \leq \mathrm{x}_{1} \leq \ell, 0 \leq \mathrm{x}_{2} \leq \mathrm{h}, 0 \leq \mathrm{x}_{3} \leq \mathrm{t}\right\} \\
\Omega^{\prime}=\left\{\left(\ell-\ell_{0}\right) / 2<\mathrm{x}_{1}<\left(\ell+\ell_{0}\right) / 2, \mathrm{x}_{2}=\mathrm{h}_{\ell}-0,\right. \\
\left.0 \leq \mathrm{x}_{3} \leq \mathrm{t}\right\} \bigcup \\
\left\{\left(\ell-\ell_{0}\right) / 2<x_{1}<\left(\ell+\ell_{0}\right) / 2, x_{2}=h_{\ell}+0,0 \leq x_{3} \leq t\right\}
\end{gathered}
$$

In this case, from the first variation of functional (5) with respect to the displacement, i.e. from the equation $\delta \Pi_{u}=0$, the equilibrium equation of (1) and the boundary conditions with respect to the forces in Eq. (2) are found. In such a way, the validity of functional (5) in the 3D FEM modeling of boundary value problems is ensured.

In the Finite Element solution by using the symmetry of $\mathrm{x}_{1}=\ell / 2$, only half-region $\Omega$ of the prism considered (Figure 1). The half part of the prism is discretized into eight-node rectangular brick finite elements (Figure 2), i. e. the region $\Omega$ is expressed as $\Omega=\bigcup_{k=1}^{M} \Omega_{k}$ where $\Omega_{k}$ is a region of the $\mathrm{k}$-th finite element. Using a normalized local coordinate system $(\mathrm{O} \xi \eta \zeta)$ the shape functions of the brick elements are written as,

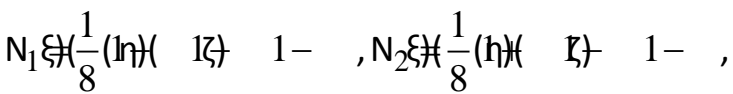

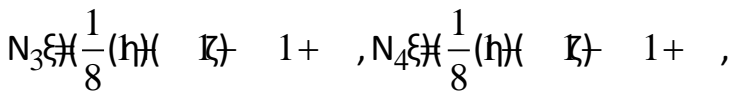

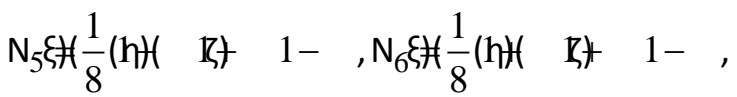

$$
\begin{aligned}
& \mathrm{N}_{7} \xi \# \frac{1}{8}(\mathrm{~h}) \text { H } \text { IH } 1+, \mathrm{N}_{8} \xi \#\left(\frac{1}{8}(\mathrm{~h})(\text { 13) } 1+\right.
\end{aligned}
$$

(Zienkiewicz and Taylor, 1989). The transformation relation between the $O \mathrm{Ox}_{1} \mathrm{x}_{2} \mathrm{x}_{3}$ and $\mathrm{O} \xi \mathrm{n} \zeta$ coordinate systems is expressed as,

$$
\xi=\frac{x_{1}-x_{10}}{\beta}, \eta=\frac{x_{2}-x_{20}}{\alpha}, \zeta=\frac{x_{3}-x_{30}}{\wp} .
$$

In Eq. (8), $x_{10} ; x_{20} ; x_{30}$ are components of the vector $\overrightarrow{\mathrm{OO}^{\prime}}$ at $O \mathrm{Ox}_{1} \mathrm{x}_{2} \mathrm{x}_{3}$ coordinate system.

In this study, it is used the displacement-based FEM, in other words, according to FEM procedure, only displacements at the nodes are supposed to be unknown. So, the displacement functions are defined as follows:

$$
u^{(k)} \approx N^{(k)} a^{(k)}, k=1,2, \ldots . M
$$


where

$$
\left(a^{(k)}\right)^{\top}=\left\{u_{11}^{k} u_{21}^{k} u_{31}^{k} u_{12}^{k} u_{22}^{k} u_{32}^{k} \ldots . . u_{18}^{k} u_{28}^{k} u_{38}^{k}\right\}
$$

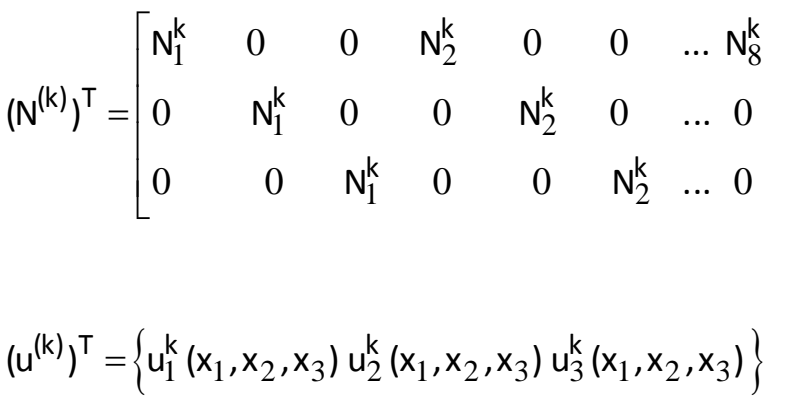

After some mathematical manipulations, finally yields the following system of algebraic equations :

\section{K}

(11)

where, $\mathbf{K}$ is the stiffness matrix, $\mathbf{a}$ is the displacement vector at finite-element nodes and $r$ is the force vector.

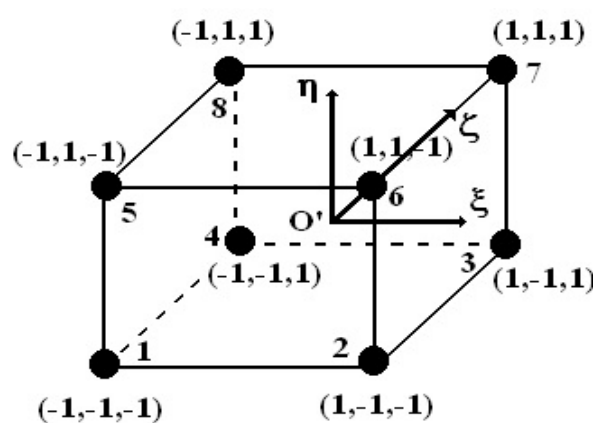

Figure 2. The geometry of brick (rectangular) finite element

After consideration of the FEM modelling, the ERR (denoted by $\gamma$ ) is calculated by using the expression:

$\gamma \approx \frac{\mathrm{U}\left(\mathrm{S}_{\mathrm{c}}+\Delta \mathrm{S}(\mathrm{s} / \mathrm{t})\right)-\mathrm{U}\left(\mathrm{S}_{\mathrm{C}}\right)}{\Delta \mathrm{S}(\mathrm{s} / \mathrm{t})}$

where

$$
\begin{aligned}
\mathrm{U}\left(\mathrm{S}_{\mathrm{c}}\right)=\frac{1}{2} \iiint_{\Omega-\Omega^{\prime}}\left(\sigma_{11} \varepsilon_{11}+2 \sigma_{12} \varepsilon_{12}+2 \sigma_{13} \varepsilon_{13}\right. \\
\left.+2 \sigma_{23} \varepsilon_{23}+\sigma_{22} \varepsilon_{22}+\sigma_{33} \varepsilon_{33}\right) \mathrm{d} \Omega
\end{aligned}
$$

$$
\begin{aligned}
& \begin{array}{ll}
0 & \mathrm{U}\left(\mathrm{S}_{\mathrm{C}}+\Delta \mathrm{S}(\mathrm{s} / \mathrm{t})\right)=\frac{1}{2} \iiint_{\Omega-\Omega^{\prime \prime}}\left(\sigma_{11} \varepsilon_{11}+2 \sigma_{12} \varepsilon_{12}\right. \\
\mathrm{N}_{8}^{\mathrm{k}} & 0
\end{array} \\
& +2 \sigma_{13} \varepsilon_{13}+2 \sigma_{23} \varepsilon_{23} \\
& \left.+\sigma_{22} \varepsilon_{22}+\sigma_{33} \varepsilon_{33}\right) \mathrm{d} \Omega
\end{aligned}
$$

In the above expressions, $U$ denotes the strain energy, $\mathrm{S}_{\mathrm{c}}$ is the area of the crack's edge surface.

First, we calculate the strain energy for the unperturbed case using (13). Then, we apply a small perturbation (area of which is defined by $\Delta S(s / t)$ which is itself determined by the parameter $s / t$ on the crack front ) on the area of the crack surface and calculate the strain energy again for the perturbed case using (14). It should be noted that the arc length co-ordinate $S$ is measured along the crack front from the center of the crack $(\mathrm{s}=0)$ to the point where it reaches the free surface $(\mathrm{s}=\mathrm{t} / 2)$. The domains $\Omega$ and $\Omega^{\prime}$ in (12) are determined by the expressions in (6), $\Omega^{\prime \prime}=\left(\Omega^{\prime}+\Omega_{\Delta S(\mathrm{~s} / \mathrm{t})}\right)$ and $\Omega_{\Delta S(\mathrm{~s} / \mathrm{t})}$ are the domains corresponding to the aforementioned perturbation of the crack's edge area.

In the calculation procedure, the $\Delta \mathrm{S}(\mathrm{s} / \mathrm{t})$ values are chosen small enough to ensure the numerical convergence. The values of $\gamma$ for various values of $\Delta \mathrm{S}(\mathrm{s} / \mathrm{t})$ are calculated. Obviously, the results are improved with smaller $\Delta \mathrm{S}(\mathrm{s} / \mathrm{t})$. Moreover, dimensionless Energy Release Rate (denoted by ERR) is used and this parameter is defined by $\operatorname{ERR}=\frac{\gamma}{E_{1}}$

\section{Numerical Results}

Before obtaining numerical results, the PC programs composed and used by the author are tested on the problems considered in Sukumar et al. (2000) and Li et al. (1998). To allow comparison with corresponding numerical results Sukumar et al. (2000) and Li et al. (1998), first, it is considered a 
rectangular prism which contains a single edge crack. The top and bottom surface of this prism impose uniformly distributed normal forces as shown Figure 3. The geometrical parameters are taken as $\ell_{0} / \ell=0.5, \mathrm{t} / \ell=0.75$ and $\mathrm{h} / \ell=0.875$.

In Figure 4, the values of the SIF for the mode I for isotropic case i.e. $\mathrm{E}_{1}=\mathrm{E}_{2}=\mathrm{E}_{3}=\mathrm{E}$, $v_{12}=v_{13}=v_{23}=v, G_{12}=E /(2(1+v))$ and $v=0.3$ are presented and comparisons with the results obtained by Sukumar et al. (2000) and Li et al. (1998) are shown. Here, two different finite meshes are considered in the FEM model a) Mesh 1 consists of $20 \times 20 \times 20$ brick elements and b) Mesh 2 consists of $24 \times 24 \times 24$ brick elements along the $O x_{1}, O x_{2}$ and $O_{3}$ axes, respectively. As seen, in Figure 4 , there is close agreement between the results obtained and the reference solutions. Thus, it is verified the validity of the present FEM modelling and PC programs.

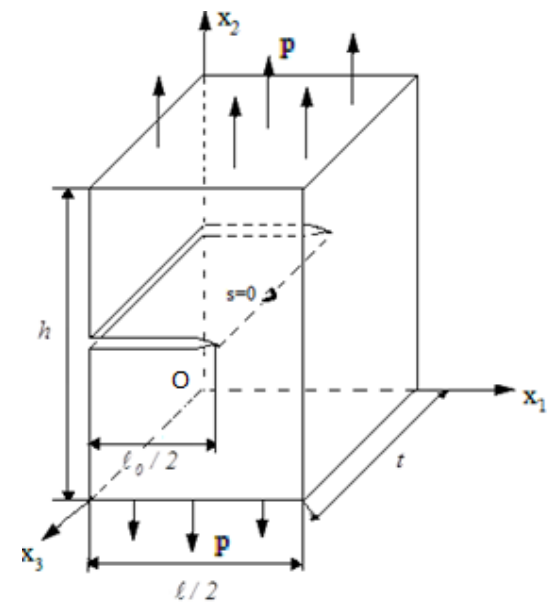

Figure 3. Edge cracked rectangular prism

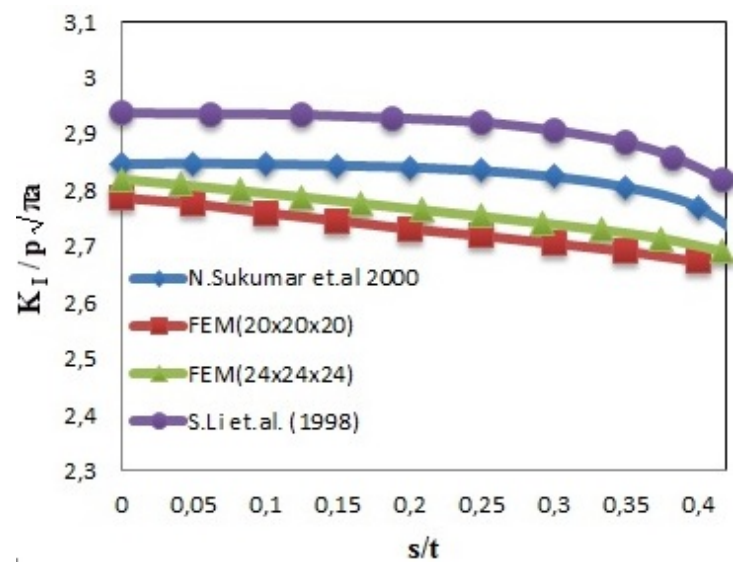

Figure 4. Comparison of the values of $\mathrm{K}_{\mathrm{I}}$ with the present study and the reference papers for the edge crack problem in isotropic case.

Now, let us focus on the band crack problem regarding to the effect of the shear modulus in a plane which is perpendicular to the crack's edgeplanes and parallel to the crack's front (i.e. in the present case the modulus $G_{23}$ ) on the values of the ERR for various parameter (Figure 1). Assume that the material of the prism is orthotropic and the numerical investigations are made for $v_{12}=v_{13}=v_{23}=0.3, \quad G_{12} / E_{1}=G_{13} / E_{1}=0.09$ ， $\mathrm{E}_{2} / \mathrm{E}_{1}=\mathrm{E}_{3} / \mathrm{E}_{1}=0.5, \quad \ell_{0} / \ell=0.5, \mathrm{t} / \ell=0.75$ and $\mathrm{h} / \ell=0.875$. The half part of the prism is discretized into brick elements with eight nodes, where the $O x_{1}$ direction is taken as 20 , the $O x_{2}$ direction is taken as 20, and the $\mathrm{Ox}_{3}$ direction is taken as 20 . The results are presented below.

The graph of the dependencies between the ERR and $s / t$ is given in Figure 5 . As can be seen in this graph that the increase of the absolute values of the ratio $\mathrm{s} / \mathrm{t}$ causes the decrease of the values of the ERR. Moreover, in Figure 5, ERR reaches maximum value (denoted by the symbol $(\star)$ ) at the center of crack (at $s / t=0$ ). This result again confirms the trustiness of the algorithm and PC programs composed by the author.

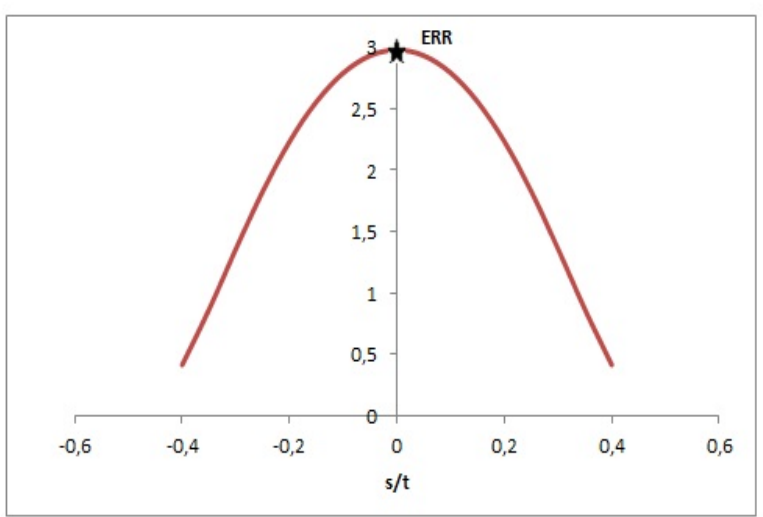

Figure 5. The graphs of the dependencies between ERR and $\mathrm{s} / \mathrm{t}$ at $\ell_{0} / 2 \ell=0.25$ and $\mathrm{G}_{23} / \mathrm{E}_{1}=0.09$

In Table 1, the effect of the ratios $G_{23} / E_{1}$ (where $\mathrm{G}_{23}$ is the shear modulus in the $\mathrm{Ox}_{2} \mathrm{x}_{3}$ plane) on 
the values of the ERR for various values of $s / t$ and $\ell_{0} / 2 \ell$ are given for the case where $h_{\ell}=h_{u}=h / 2$. It is seen that the values of the ERR significantly increase with decreasing of the ratio of $G_{23} / E_{1}$. As expected, this increase becomes more pronounced with crack length, i. e., with $\ell_{0} / 2 \ell$.

Table 1. Effect of $\mathrm{G}_{23} / \mathrm{E}_{1}$ and $\ell_{0} / 2 \ell$ on the ERR for various $\mathrm{s} / \mathrm{t}$ at $\mathrm{h}_{\ell}=\mathrm{h}_{\mathrm{u}}=\mathrm{h} / 2$.

\begin{tabular}{c|c|ccc}
\hline \multirow{2}{*}{$\ell_{\mathbf{0}} / \mathbf{2 \ell}$} & $\mathbf{s} / \mathbf{t}$ & \multicolumn{3}{|c}{$\mathbf{G}_{\mathbf{2 3}} / \mathbf{E}_{\mathbf{1}}$} \\
\cline { 3 - 5 } & & $\mathbf{0 . 0 9}$ & $\mathbf{0 . 0 6}$ & $\mathbf{0 . 0 3}$ \\
\hline \multirow{5}{*}{0.25} & 0 & 2.9810 & 5.1913 & 10.7757 \\
& 0.05 & 2.9339 & 5.1310 & 10.7416 \\
& 0.10 & 2.7930 & 4.9470 & 10.6249 \\
& 0.15 & 2.5588 & 4.6350 & 10.3799 \\
& 0.20 & 2.2345 & 4.1683 & 9.9269 \\
& 0.25 & 1.8280 & 3.5475 & 9.1470 \\
& 0.30 & 1.3587 & 2.7659 & 7.8826 \\
& 0.35 & 0.8653 & 1.8570 & 5.9731 \\
& 0.40 & 0.4142 & 0.9333 & 3.4287 \\
\hline \multirow{5}{*}{0.30} & 0 & 3.2233 & 6.0063 & 14.2036 \\
& 0.05 & 3.1701 & 5.9272 & 14.1108 \\
& 0.10 & 3.0111 & 5.6882 & 13.8175 \\
& 0.15 & 2.7490 & 5.2846 & 13.2799 \\
& 0.20 & 2.3897 & 4.7108 & 12.4246 \\
& 0.25 & 1.9451 & 3.9640 & 11.1504 \\
& 0.30 & 1.4388 & 3.0550 & 9.3359 \\
& 0.35 & 0.9133 & 2.0314 & 6.8799 \\
& 0.40 & 0.4378 & 1.0175 & 3.8692 \\
\hline
\end{tabular}

Table 2 shows the influence of the crack's location on ERR various values of $G_{23} / E_{1}$. The parameter $h_{u} / \ell$ shows the thickness of the part of the prism at the top of the crack. As seen, the values of the ERR increase with the crack moving closer to the upper face plane of the prism. This result agrees with the well-known mechanical considerations. Moreover, it also follows from this table that this effect slightly increases with decreasing of the ratio $\mathrm{G}_{23} / \mathrm{E}_{1}$.

Consider now the influence of the parameter $\mathrm{t} / \ell$ on the ERR for various $t / \ell, G_{23} / E_{1}$ and $s / t$ at $\mathrm{h}_{\ell}=\mathrm{h}_{\mathrm{u}}=\mathrm{h} / 2$ and $\ell_{0} / 2 \ell=0.25$; where $\mathrm{t} / \ell$ is the length of the prism along the $\mathrm{Ox}_{3}$ axis. These results are given in Table 3 . It is seen that the values of the ERR increase with an increase of the parameter $\mathrm{t} / \ell$. A decrease of the ratio of the $G_{23} / E_{1}$ causes a decrease in the influence of the parameter $\mathrm{t} / \ell$ on the ERR.

Table 3. Effect of $G_{23} / E_{1}$ and $t / \ell$ on the $E R R$ for various $\mathrm{s} / \mathrm{t}$ at $\ell_{0} / 2 \ell=0.25$ and $\mathrm{h}_{\ell}=\mathrm{h}_{\mathrm{u}}=\mathrm{h} / 2$.

\begin{tabular}{c|c|cc}
\hline & & \multicolumn{2}{|c}{$\mathbf{t} / \ell$} \\
\cline { 3 - 4 } $\mathbf{G}_{\mathbf{2 3}} / \mathbf{E}_{\mathbf{1}}$ & $\mathbf{s} / \mathbf{t}$ & $\mathbf{0 . 7 5}$ & $\mathbf{1}$ \\
\hline & 0 & 2.9810 & 4.6663 \\
& 0.05 & 2.9339 & 4.6093 \\
& 0.10 & 2.7930 & 4.4361 \\
0.09 & 0.15 & 2.5588 & 4.1410 \\
& 0.20 & 2.2345 & 3.7158 \\
& 0.25 & 1.8280 & 3.1535 \\
& 0.30 & 1.3587 & 2.4566 \\
& 0.35 & 0.8653 & 1.6563 \\
& 0.40 & 0.4142 & 0.8463 \\
\hline \multirow{3}{*}{0.06} & 0 & 5.1913 & 6.4221 \\
& 0.05 & 5.1310 & 6.3786 \\
& 0.10 & 4.9470 & 6.2414 \\
& 0.15 & 4.6350 & 5.9902 \\
& 0.20 & 4.1683 & 5.5905 \\
& 0.25 & 3.5475 & 4.9947 \\
& 0.30 & 2.7659 & 4.1477 \\
& 0.35 & 1.8570 & 3.0144 \\
& 0.40 & 0.9333 & 1.6651 \\
\hline
\end{tabular}

Table 2. The effect of $h_{u} / \ell$ and $G_{23} / E_{1}$ on the ERR for various values of $\mathrm{s} / \mathrm{t}$ at $\ell_{0} / 2 \ell=0.25$.

\begin{tabular}{c|cccc|cccc}
\hline \multirow{3}{*}{$\mathbf{s} / \mathbf{t}$} & \multicolumn{9}{|c}{$\mathbf{G}_{\mathbf{2 3}} / \mathbf{E}_{\mathbf{1}}$} \\
\cline { 2 - 9 } & \multicolumn{3}{|c}{$\mathbf{0 . 0 9}$} & \multicolumn{4}{c}{$\mathbf{0 . 0 3}$} \\
\cline { 2 - 9 } & \multicolumn{3}{|c}{$\mathbf{h}_{\mathbf{u}} / \boldsymbol{\ell}$} & \multicolumn{3}{c}{$\mathbf{h}_{\mathbf{u}} / \boldsymbol{\ell}$} \\
\cline { 2 - 9 } & $\mathbf{0 . 4 3 7 5}$ & $\mathbf{0 . 3 0 6 2 5}$ & $\mathbf{0 . 2 6 2 5}$ & $\mathbf{0 . 1 7 5}$ & $\mathbf{0 . 4 3 7 5}$ & $\mathbf{0 . 3 0 6 2 5}$ & $\mathbf{0 . 2 6 2 5}$ & $\mathbf{0 . 1 7 5}$ \\
\cline { 2 - 9 } 0 & 2.9810 & 3.4845 & 3.9792 & 6.2703 & 10.7757 & 11.6841 & 12.4756 & 15.4977 \\
0.05 & 2.9339 & 3.4307 & 3.9188 & 6.1787 & 10.7416 & 11.6535 & 12.4488 & 15.4881 \\
0.10 & 2.7930 & 3.2698 & 3.7381 & 5.9045 & 10.6249 & 11.5452 & 12.3502 & 15.4346 \\
0.15 & 2.5588 & 3.0029 & 3.4360 & 5.4500 & 10.3799 & 11.3078 & 12.1234 & 15.2612 \\
0.20 & 2.2345 & 2.6334 & 3.0267 & 4.8216 & 9.9269 & 10.8515 & 11.6692 & 14.8338
\end{tabular}




\begin{tabular}{l|llll|llll}
0.25 & 1.8280 & 2.1702 & 2.5038 & 4.0336 & 9.1470 & 10.0438 & 10.8426 & 13.9560 \\
0.30 & 1.3587 & 1.6324 & 1.8986 & 3.1133 & 7.8826 & 8.7142 & 9.4588 & 12.3777 \\
0.35 & 0.8653 & 1.0582 & 1.2468 & 2.1097 & 5.9731 & 6.6928 & 7.3366 & 9.8543 \\
0.40 & 0.4142 & 0.5177 & 0.6211 & 1.1091 & 3.4287 & 3.9526 & 4.4238 & 6.2664 \\
\hline
\end{tabular}

As seen from the tables, the effect of the problem parameters on the ERR is more considerable at the center of the crack $(s=0)$ than at the points that are close to the free face planes.

\section{Conclusions}

Thus, in the present paper we deal with rectangular orthotropic prism under the action of the uniformly distributed normal forces on the upper and lower face planes with a band crack. The investigation is focused on the effect shear modulus in a plane which is perpendicular to the crack's edge-planes and parallel to the crack's front (i. e. the modulus $G_{23}$ ) and geometrical parameters on the ERR. By employing the threedimensional FEM modeling, the corresponding boundary-value problem is solved. The mathematical formulation of the corresponding boundary value problems is presented within the scope of the three-dimensional linear theory of elasticity for anisotropic bodies. Based on these analyses, the following concrete conclusions can be drawn:

- The values of the ERR significantly increase with decreasing of the shear modulus in a plane which is perpendicular to the crack's edgeplanes and parallel to the crack's front (i. e. the modulus $G_{23}$ ). This increase is more influenced with crack length;

- The values of the ERR increase as the crack approaches the free upper face of the prism. This increase is larger with decreasing $\mathrm{G}_{23}$;

-The effect of the problem parameters to the ERR at the center of the crack, i.e. at $s / t=0$ is more notable than at the points that are close to the free face surface of the prism; and

- The values of the ERR increase with increasing of the length of the prism along the $\mathrm{Ox}_{3}$ axis.

\section{References}

Akbarov, S.D. and Turan, A. , 2009. Mathematical modelling and the study of the influence of initial stresses on the SIF and ERR at the crack tips in a plate-strip of orthotropic material. Applied Mathematical Modelling, 33(9), 3682-3692.

Cherepanov, G. P., 1967. The propagation of cracks in a continuous medium. Journal of Applied Mathematics and Mechanics, 31(3), 503-512.

Ding S.H. and Li. X., 2014. The collinear crack problem for an orthotropic functionally graded coating-substrate structure. Archive of Applied Mechanics, 84(3), 291-307.

Fan C., Jar P.Y.B. and Cheng J.J.R., 2007. Prediction of energy release rates for crack growth using FEM-based energy derivative technique. Engineering Fracture Mechanics, (74)8, 12431254.

Gosz M., Dolbow J. and Moran B., 1998.Domain integral formulation for stress intensity factor computation along curved three-dimensional interface cracks. International Journal of Solids and Structures, 35(15)1763-1783.

Knowles, J.K. and Sternberg E., 1972. On a Class of Conservation Laws in Linearized and Finite Elastostatics. Archive for Rational Mechanics and Analysis (44)3, 187-211.

Lekhnitskii S. G., 1981. Elasticity Theory of Anisotropic Bodies, (in Russian), Mir, Moscow.

Li S., Mear M.E. and Xiao L., 1998. Symmetric weak-form integral equation method for three- 
dimensional fracture analysis. Computer Methods in Applied Mechanics and Engineering, 151(3-4), 435-459.

Maiti S.K., 1992. Finite element computation of crack closure integrals and stress intensity factors. Engineering Fracture Mechanics, 41(3), 339-348.

Oneida E.K., van der Meulen M.C.H and Ingraffea A.R., 2015. Method for calculating $G, G_{1}$, and $G_{\|}$to simulate crack growth in $2 D$, multiplematerial structures. Engineering Fracture Mechanics, (140), 106-126.

Rice, J. R., 1968. A path independent integral and the approximate analysis of strain concentration by notches and cracks. Journal of Applied Mechanics, 35(2), 379-386.

Shivakumar K.N., Tan P.W., and Newman J.C., 1988. A virtual crack-closure technique for calculating stress intensity factors for cracked three dimensional bodies. International. Journal Fracture, 36(3), R43-R50.

Sih G., 1973. Handbook of Stress Intensity Factors, Lehigh University.

Sukumar N., Moes N., Moran B. and Belytschko T., 2000. Extended finite element method for threedimensional crack modeling. International Journal for Numerical Methods Engineering, 48(11), 1549-1570.

Tada, H., Paris, P. C. and Irwin, G. R., 1985. The Stress Analysis of Cracks Handbook. 2nd ed., Paris Productions Inc., St. Louis, Missouri

Yusufoglu E. and Turhan I.,2012 . A mixed boundary value problem in orthotropic strip containing a crack. Journal of the Franklin Institute, 349(9), 2750-2769.

Zienkiewicz O. C. and Taylor R L., 1989. The Finite Element Method- $4^{\text {th }}$ Ed. Vol. 1, Basic
Formulation and Linear Problems, London: McGraw-Hill Book Company. 